EGU21-14547

https://doi.org/10.5194/egusphere-egu21-14547

EGU General Assembly 2021

(c) Author(s) 2021. This work is distributed under

the Creative Commons Attribution 4.0 License.

\title{
Understanding urban hydrology through measurements of infiltration capacity of permeable pavements under real-live circumstances
}

Ted Veldkamp ${ }^{1}$, Floris Boogaard ${ }^{2,3,4}$, Rutger de Graaf ${ }^{5}$, and Jeroen Kluck ${ }^{1,6}$

${ }^{1}$ Centre of Expertise Urban Technology, Amsterdam University of Applied Sciences, Amsterdam, the Netherlands

(t.i.e.veldkamp@hva.nl)

${ }^{2}$ School of Architecture, Built Environment \& Civil Engineering, Hanze University of Applied Sciences, Groningen, the Netherlands

${ }^{3}$ Global Center on Adaptation, Groningen, the Netherlands

${ }^{4}$ Deltares, Delft, the Netherlands

${ }^{5}$ Research Centre Sustainable Port City, Rotterdam University of Applied Sciences, Rotterdam, the Netherlands

${ }^{6}$ TAUW, Deventer, the Netherlands

Over the past decades various types of permeable pavements have been implemented in different municipalities in the Netherlands in order to improve infiltration capacity in urban areas and therewith being able to better treat stormwater runoff. With initial promising results this adaptation measure seemed to be the solution for urban flooding due to extreme precipitation. However, in practice, foreseen infiltration capacities were usually not met, often due unknown reasons.

To better understand the functioning of permeable pavements in practice, we have studied - as part of the project Infiltrating Cities - over 100 existing permeable pavement installations in the Netherlands. At each location, infiltration capacity was tested through a full-scale infiltration testing procedure (flooded area about $40 \mathrm{~m}^{2}$ ) while conditional on-site factors were collected (location, age, type of permeable pavement, street-type, traffic density, vicinity of urban green, regular maintenance regime, etc.). By coupling this information we analyzed how these factors influence the infiltration capacity of permeable pavements in practice, e.g. through accelerated deterioration of infiltration capacity through time. In addition, we evaluated for a selected number of installations, how various types of maintenance may counteract this deterioration, hence improving the infiltration capacity of permeable pavements.

Most of he studied permeable pavements function, with an average infiltration capacity of 540 $\mathrm{mm} /$ hour, above Dutch and international standards. However, the observed variation in measured infiltration capacity is high (35 mm/hour - $5707 \mathrm{~mm} /$ hour) and cannot alone be explained by differences in age of the permeable pavement installations studied. Our analysis shows that also the deterioration-rate of the measured infiltration capacity, with an average of $74 \mathrm{~mm} / \mathrm{hour}$ per year, varies substantially among installations, caused by factors like the vicinity of urban green, 
traffic density, and maintenance regime. The results have been compared to international studies finding similar conclusions about infiltration capacity and dominant factors, but little information is available of the effect of maintenance to recover the initial infiltration capacity. Evaluating the infiltration capacity after the application of various maintenance techniques shows us that applying the right maintenance regime to permeable pavements may improve infiltration capacity with an average of 380 percent. Especially in the case of under-performing permeable pavements this may be the key to improving the functioning and lifetime of permeable pavements in practice.

Our results can be used to improve model representations of urban hydrological processes, give insights in potential adaptation strategies to deal with challenges related to (extreme) precipitation, and provide guidelines to city design in the light of climate change and rapid urbanization. Hence, various disciplines and user-groups can benefit from our outcomes: From the hydrological scientists aiming at improving the representation of urban hydrological processes in models order to better understand and predict how (extreme) precipitation may lead to urban flooding - now and in the future; to the urban water managers who are about to decide on the optimal strategy to deal with extreme precipitation and minimize urban flooding; and finally, to the urban designers that are developing resilient designs for future-proof cities. 